\title{
Estimating safe scaled distances for columns subjected to blast
}

Michael Byfield BEng,PhD,CEng,MIStructE and Sakthivel Paramasivam BEng, PhD, MSc

Faculty of Engineering and the Environment

University of Southampton

\begin{abstract}
This paper is concerned with determining the minimum stand-off distance required to prevent column failures in reinforced concrete framed buildings. This is of interest because column failures can initiate progressive collapse resulting in mass casualties. A technique is developed to determine the critical range at which failure will occur for a given weight of explosives and thus provide a safe scaled distance. The method is used to carry out a parametric study of a range of reinforced concrete columns of variable dimensions and strengths. The corresponding data were used to predict safe scaled distances for columns (with and without clearing). These values can be used to estimate the minimum stand-off distance required to prevent progressive collapses of buildings that may be subjected to deliberate blast loading.
\end{abstract}

\section{Introduction}

The most effective means of protecting buildings against vehicle borne improvised explosive devices (VBIED's) is to maximise the distance between the explosive and the structure. This is often ensured by the installation of barriers, such as the soil filled (HESCO) gabions used by NATO expeditionary forces. The distance between the barrier and the building is commonly termed "set-back" in the USA and "stand-off" in the UK. The Hopkinson and Cranz scaling laws (Hopkinson 1915, Cranz 1926) show that over-pressure can be predicted from the range $(\mathrm{R})$ divided by the cubed root of the mass of the explosive $\left(\mathrm{W}^{1 / 3}\right)$. This leads to the concept of scaled distance, $\mathrm{Z}=\mathrm{R} / \mathrm{W}^{1 / 3}$, in which the overpressure produced by different charge sizes would be identical for the same scaled distance $(Z)$. Since damage is a function of over-pressure the scaled distance is a useful parameter for setting stand-off distances because it allows the mass of the explosive to be varied.

Guidance as to what value stand-off should take varies, with the US DoD recommending a scaled distance of not less than $4.46 \mathrm{~m} / \mathrm{kg}^{1 / 3}\left[11.24 \mathrm{ft} / \mathrm{lbs}^{1 / 3}\right]$ (US DoD, 2004). This can be a restrictive limit and would for example require $45 \mathrm{~m}$ of stand-off to be provided for a design charge weight of $1000 \mathrm{~kg}$ (TNT). Within this range masonry load bearing buildings are at significant risk of collapse, although r.c. framed buildings are known to survive at scaled distances well within this limit. UK research into blast effects on steel and r.c. framed buildings during World War 2 was led by Sir Dermot Christopherson, who suggested 'the region $1<Z<5 \mathrm{ft} / \mathrm{lbs}{ }^{1 / 3}\left[0.4<Z<1.98 \mathrm{~m} / \mathrm{kg}^{1 / 3}\right]$ is of first-rate importance to the designer'. At a range of less than $0.4 \mathrm{~m} / \mathrm{kg}^{1 / 3}$ the target was defined as 
being within the explosive flame and outside the scope of normal design measures, whereas the upper limit of $1.98 \mathrm{~m} / \mathrm{kg}^{1 / 3}$ is of interest as within this limit failure of framing members is likely.

Buildings subjected to large blasts include the Marriott Hotel in Islamabad which was subjected to a $4.4 \mathrm{~m} / \mathrm{kg}^{1 / 3}\left[11 \mathrm{ft} / \mathrm{lbs}^{1 / 3}\right]$ blast in 2008 and the Police \& Internal Affairs Building in the Republic of Ingushetia, Russia which received a $2.4 \mathrm{~m} / \mathrm{kg}^{1 / 3}\left[5.3 \mathrm{ft} / \mathrm{lbs}^{1 / 3}\right]$ blast in 2009 . Neither of these buildings suffered structural damage to their supporting frames due to blast. Many progressive collapses of framed buildings subjected to VBIED's have been triggered by the failure of columns, as occurred in the Alfred P. Murrah Federal Building in 1995, in which the failure of 3 perimeter columns led to a collapse of nearly $1 / 2$ of the floor area. The scale of this disaster has previously been blamed on the use of a transfer girder to support every other perimeter column, Corley, W. G. et al (1998). However, recent blast analysis of the building, in which the transfer girder was removed to allow all perimeter columns to continue down to ground floor level has demonstrated that the VBIED detonated would still have created a $42 \mathrm{~m}$ wide collapsed section of the building, Byfield and Paramasivam (2011). The work demonstrated that lack of redundancy was key to the collapse, because the building used open-plan architecture with a fully glazed façade.

Knowledge of the scaled distance at which reinforced concrete columns begin to fail is of practical interest in the recommending of a bare minimum stand-off distance for use in congested urban areas. This paper aims to determine this stand-off distance by exploring the failure of r.c. columns. A method is presented for determining at what scaled distance the balance point between survival and failure occurs. This is termed the Safe Scaled Distance (SSD).

\section{The Safe Scaled Distance (SSD) approach}

In the present work the estimation of a SSD for a given column and threat is by iteration. For a given charge weight an initial range is assumed and the blast wave parameters such as reflected pressure determined. If the dynamic analysis reveals that the shear force is greater than the shear strength or the moment is greater than the flexural strength, then the column is deemed unsafe and the stand-off distance increased. This procedure is repeated until the strength of the column is exactly equal to the dynamic force developed in the column. This process is explained graphically in Fig 1 for the case of shear failure with a constant charge weight. The dynamic shear force experienced by the column and shear capacity are non-dimensionalized by dividing by the total applied load, which is equal to the column face area multiplied by the peak reflected pressure. These normalised forces are plotted against the ratio between the blast time duration and the natural period of vibration of the column $\left(t_{d} / t_{n}\right)$. This ratio governs the degree of impulsiveness and it also affects the ratio between shear strength and load, since the loading falls as the range increases. The intersection between the two graphs provides the value of $t_{d} / t_{n}$ which corresponds to the SSD. Once the critical $t_{d} / t_{n}$ ratio is defined 
it is subsequently a trivial procedure to define the range that corresponds to the given charge weight of explosives.

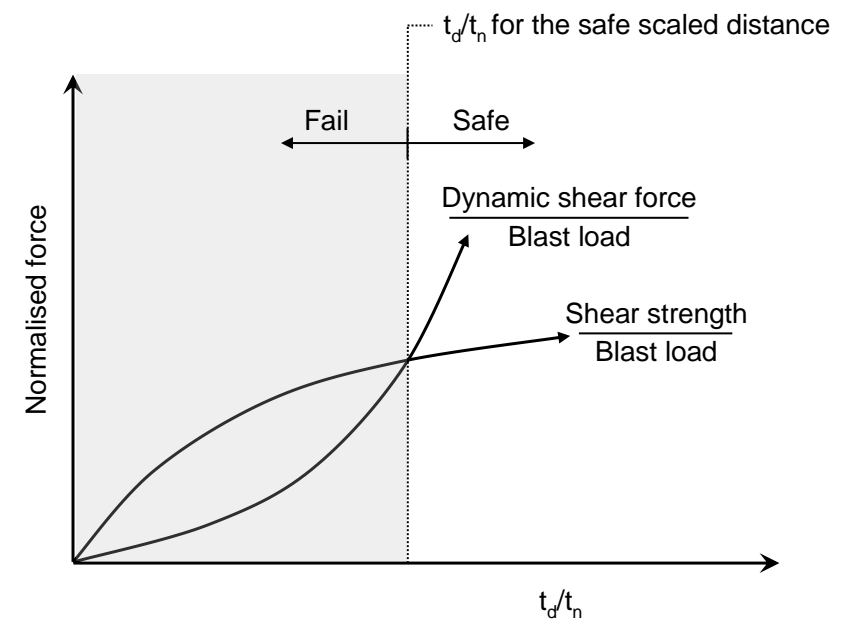

Fig. 1 Safe stand-off distance considering shear failure

\section{Calculating the dynamic shear force and moment}

During the assessment of shear failure the columns have been assumed to remain linear elastic up until shear failure at the supports. This assumed response is supported by observations from bomb damaged structures. The forensic investigation of the Murrah building showed that two perimeter columns failed by shear and the closest to the blast failed by brisance. The perimeter columns which failed by shear were found to have remained largely elastic along their lengths (Corley, 1998). Similar failures were observed during the forensic investigations carried out on bomb damaged buildings during World War 2, Byfield (2004, 2006) and Smith et al (2010). Fig. 2 shows bomb damaged columns which have experienced shear failures at the ceiling level but which have remained uncracked along their lengths. The assumption is conservative because linear-elastic response produces a shorter natural period of vibration than elastic-plastic response. This leads to a higher dynamic shear force because the ratio of $t_{d} / t_{n}$ is increased, which means the loading is less impulsive. In other words, by remaining elastic, shear failure at the supports is able to occur faster and at a lower load. In contrast, the dynamic analysis for flexural response was carried out assuming elasto-plastic response. The analysis reported herein demonstrated that shear failure of columns always occurred at lower scaled distances than for flexural failure. Since shear failure was always found to be critical the detailed information on the analysis for flexure is not presented herein, but it is available in Paramasivam (2008). 

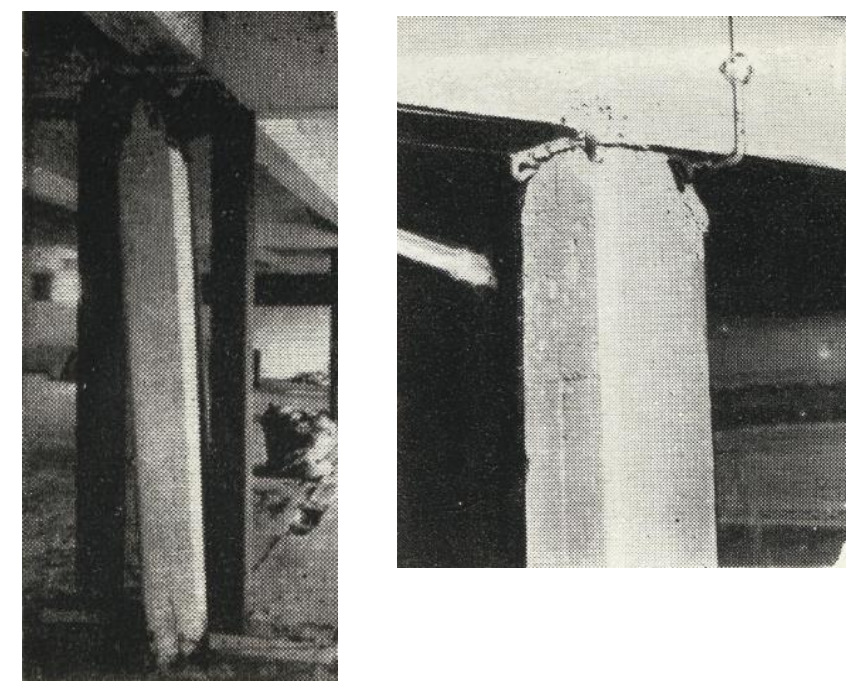

Fig. 2: Shear failures due to blast (Baker, 1948)

The columns were modelled using the standard distributed mass method defined in many textbooks such as Biggs (1964) and more recently by Chopra (2001). In this method the partial differential equation (Eq. 1) is developed using force equilibrium and the response $u(x, t)$ is expressed as the superposition of the response of individual modes. For RC columns, the shear deformation and the effect of axial compression on the dynamic response are negligible, hence ignored.

$$
\begin{aligned}
& m \frac{\partial^{2} u}{\partial t^{2}}+E I \frac{\partial^{4} u}{\partial x^{4}}=P[x, t] \\
& u[x, t]=\sum_{n=1}^{\alpha} \phi_{n}[x]_{n} q[t]
\end{aligned}
$$

In this study the response (u) was obtained by combining these standard time and spatial functions to form the following expressions for columns:

$$
\begin{aligned}
& u[x, t]=\frac{-4 P L^{3}}{\pi^{5} E I} \sum_{n=1,3,5, \ldots}^{\alpha} \frac{1}{n^{5}}\left(\frac{\sin \left[\omega_{n} t\right]}{\omega_{n} t_{d}}-\cos \left[\omega_{n} t\right]+\frac{t_{d}-t}{t_{d}}\right) \sin \left[\frac{n \pi x}{L}\right] \\
& u[x, t]=\sum_{n=1,3,5, \ldots}^{\alpha}\left(\frac{u_{n}\left[t_{d}\right]}{\omega_{n}} \sin \left[\omega_{n}\left(t-t_{d}\right)\right]+u_{n}\left[t_{d}\right] \cos \left[\omega_{n}\left(t-t_{d}\right)\right]\right) \sin \left[\frac{n \pi x}{L}\right]
\end{aligned}
$$

Where,

$$
u_{n}\left[t_{d}\right]=\frac{2 P}{m L \omega_{n}^{2} \pi} \frac{\left((-1)^{n}-1\right)}{n}\left[\frac{\sin \left[\omega_{n} t_{d}\right]}{\omega_{n} t_{d}}-\cos \left[\omega_{n} t_{d}\right]\right]
$$


$\dot{u}_{n}\left[t_{d}\right]=\frac{2 P}{m L \omega_{n} \pi} \frac{\left((-1)^{n}-1\right)}{n}\left[\frac{\cos \left[\omega_{n} t_{d}\right]}{\omega_{n} t_{d}}-\sin \left[\omega_{n} t_{d}\right]-\frac{1}{\omega_{n} t_{d}}\right]$

$L \quad$ Length of the column

$m \quad$ Mass per unit length

$n \quad$ Mode number

$P[t] \quad$ Blast load on column per metre length at time, ' $\mathrm{t}$ '

$u \quad$ Displacement

$\omega_{n} \quad$ Natural frequency of $\mathrm{n}^{\text {th }}$ mode

EI flexural stiffness

If the duration of the blast is quasi-static the maximum response occurs before the load diminishes to zero and the maximum response of an idealized column pinned at both ends was calculated using Eq. 3. This equation was used up to time $t_{d}$. In cases where the maximum deflection occurs after the load has diminished to below zero the response after was calculated using Eq. 4. Shear forces and moments were calculated from these displacement functions by solving the governing beam equations.

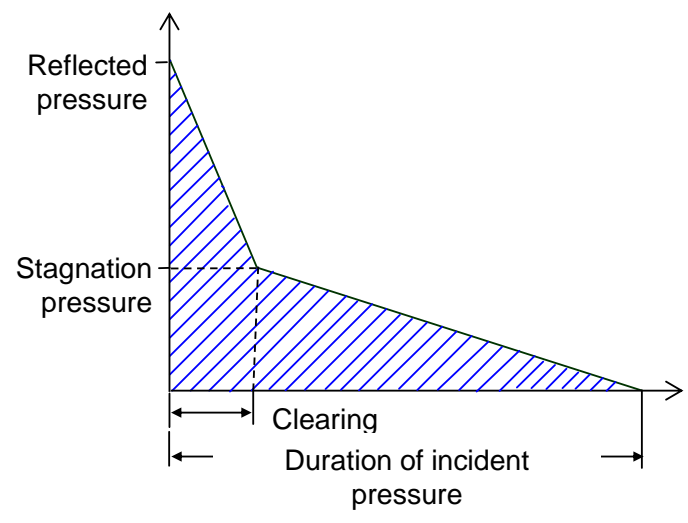

(a) Blast pressure on front face

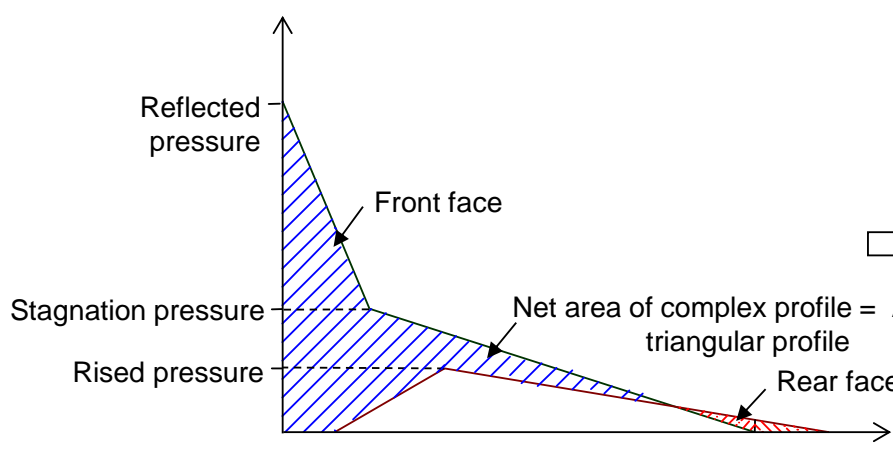

(c) Net pressure on column

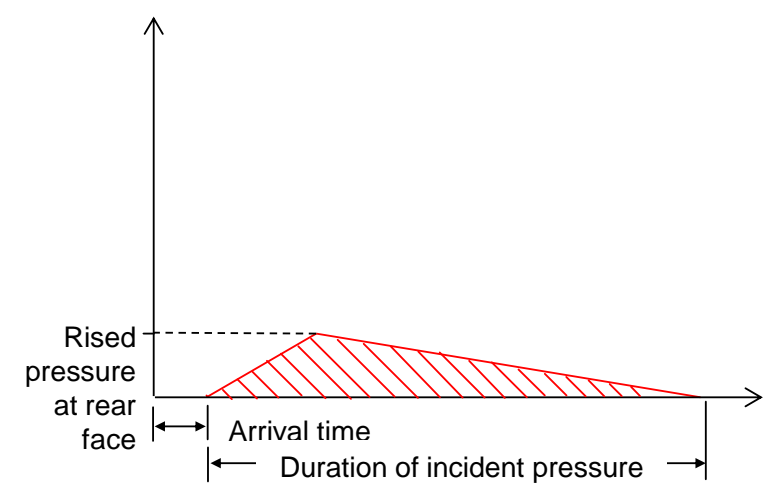

(b) Blast pressure on rear face

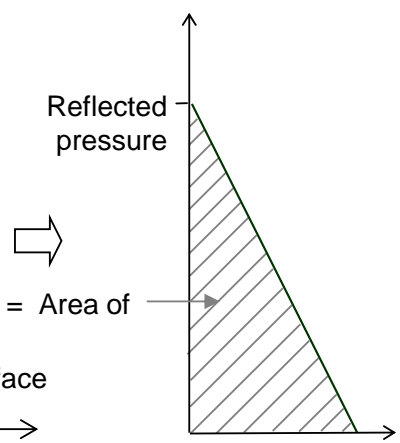

(d) Idealized blast load on column

Fig. 3: Blast Load on Column 
During the analysis for shear the uncracked transformed section moment of inertia was used in the calculation of the natural time period $\left(I_{g}+I_{s}\right)$, where $I_{g}$ is the gross moment of inertia and $I_{s}$ is the second moment of transformed area of reinforcement. During the analysis for flexural failure the cracking of concrete is important in reducing stiffness and increasing the natural time period of vibration and thus reducing peak moments on the column. In the present analysis the US DoD (2008) approach for flexure of using average moment of inertia of the cracked and uncracked sections was used.

\section{Defining the blast loading}

This investigation considered conditions in which the reflected pressure was or was not free to clear either side of the column. In columns that are free to clear the net load on the column (see the hatched area in Fig. 3(c)) is the front side load (Fig. 3(a)) minus the rear side load (Fig. 3(b)). Various graphs are available to estimate air blast loads (Kingery, 1984, Brode, 1955 and Henrych, 1979). In the present investigation blast wave parameters were based on the equations developed by Kingery (1984). Load duration is governed by the velocity of the wave front and the clearance distance, as the blast wave clears quickly if the blast wave is free to wrap around the column. For the work presented in this paper the complex pressure-time history shown by the hatched region of Fig. 3(c) was converted into a simple triangular pulse of equivalent area (impulse), as sketched in Fig. 3(d). The time duration $\left(t_{d}\right)$ for the triangular pulse was calculated by dividing the impulse (net area under pressure-time curve) by the peak reflected pressure. In other words $t_{d}$ is the effective time duration inclusive of clearing effects. To study the inaccuracy resulting from this simplification, a parametric study was carried out (Paramasivam 2008) which showed that the approximation is conservative and the error is within ten percent.

\section{Application of the method to a real building}

The Murrah Building incident was reanalysed to illustrate the approach. The blast load $(W)$ and its duration $\left(t_{d}\right)$ were estimated for various stand-off distances ( 3 to $50 \mathrm{~m}$ ) with the charge size corresponding to that used in the original incident $(1800 \mathrm{~kg}$ TNT equivalent). The shear capacity of the columns was calculated assuming an axial compression force resulting from full unfactored dead loads $+1 / 3^{\text {rd }}$ unfactored imposed loads. Using the approach (Fig. 1) the normalised shear force and strength were plotted against $t_{d} / t_{n}$. The intersecting point shown in Fig. 4(a) occurred at $t_{d} / t_{n}=0.17$ which yielded a safe stand-off distance of $23.75 \mathrm{~m}$ (Fig. 4(b)). The forensic investigation of the building showed column G16 (range $15.24 \mathrm{~m}$, scaled distance $1.25 \mathrm{~m} / \mathrm{kg}^{1 / 3}$ ) failed in shear, whereas the next closest column G12 (range $27.13 \mathrm{~m}$, scaled distance $2.23 \mathrm{~m} / \mathrm{kg}^{1 / 3}$ ) survived. This corresponds to what was observed on the actual building and provides some confidence in the solution. Shear 
failure was found to be critical over flexural failure and the safe scaled distance (SSD) for the building (against progressive collapse) was shown to be $1.95 \mathrm{~m} / \mathrm{kg}^{1 / 3}$, which is remarkably close to Christopherson's value of $1.98 \mathrm{~m} / \mathrm{kg}^{1 / 3}$.

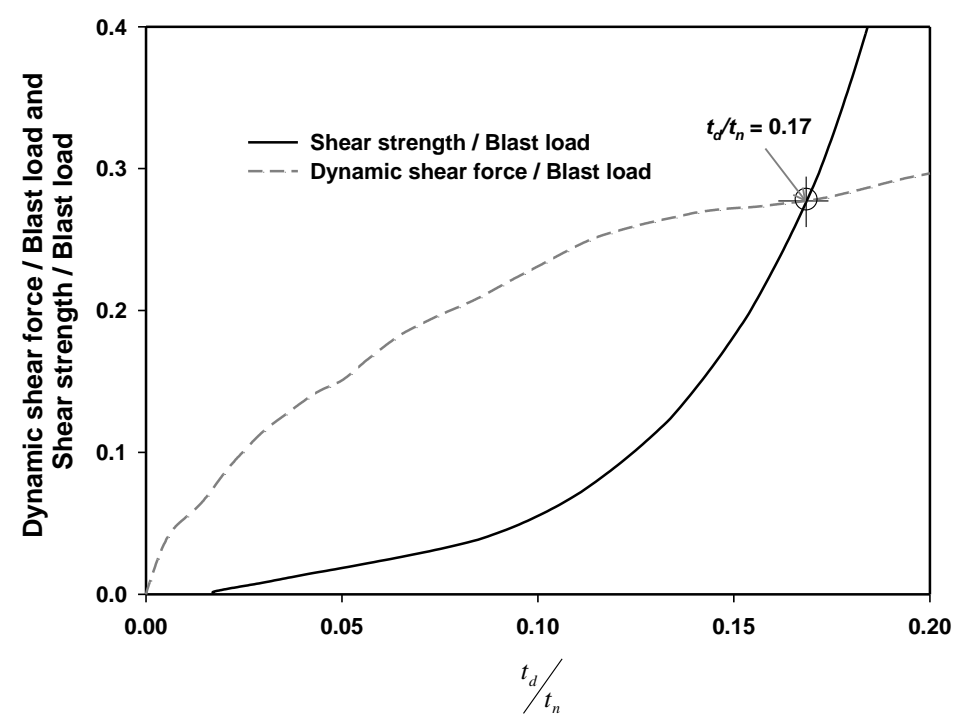

(a) Calculation of critical $t_{d} / t_{n}$ ratio for the Murrah Building

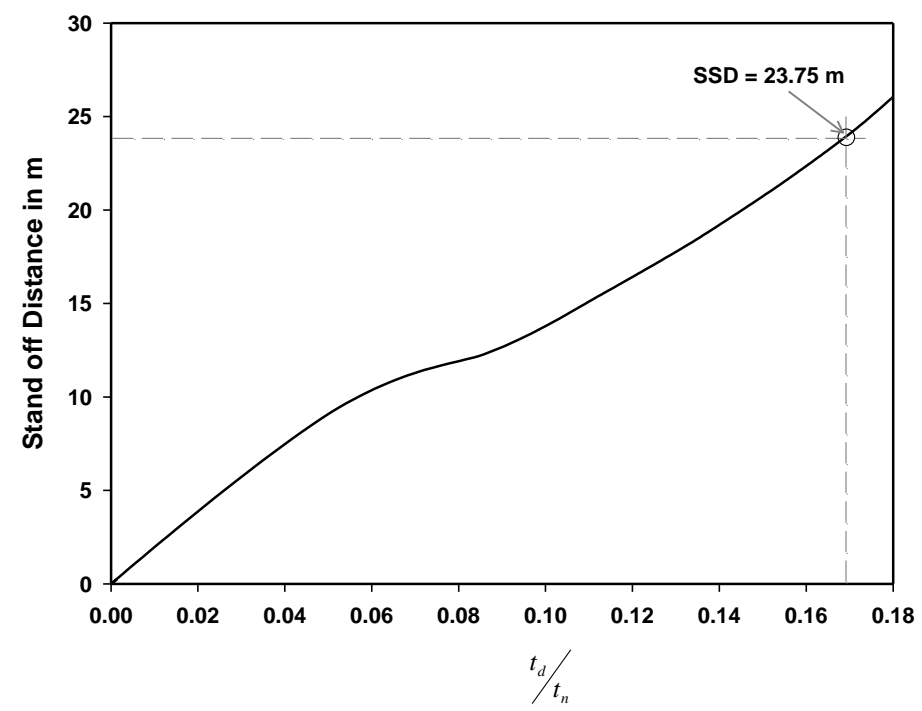

(b) Calculation of SSD from the given $t_{d} / t_{n}$ ratio

Fig. 4 Safe scaled distance for the Murrah building

Parametric study to determine a general design value for the scaled distance for reinforced concrete columns

This method for calculating SSD is complex and not for rapid use. Therefore is becomes necessary to create interpolation functions for predicting the SSD for a given set of input parameters. The first step in developing an expression is to identify the influencing parameters. The dynamic shear force can be mathematically represented as follows, 


$$
\begin{aligned}
& V=f_{1}\left[W, B / L, D / L, L, I_{t} / I_{g}, f_{c k}, S D\right] \\
& V=f_{2}\left[W, D / L, L, \frac{I_{t}}{I_{g}}, f_{c k}, S D\right]
\end{aligned}
$$

(Non clearing)

Where:

$I_{t} \quad$ is the second moment of area for the transformed section

$I_{g} \quad$ is the second moment of area for gross concrete section

$B \quad$ is the column breadth

$D \quad$ is the column depth

$L \quad$ is the column length

$f_{c k} \quad$ is the characteristic cube compressive strength

$S D$ is the stand of distance

$W$ is the charge weight

For simplicity this is not broken down into sub parameters such as area of compression steel, cover thickness etc. The explanation for the decision to divide $B$ by $L$ and $D$ by $L$ in this list of influencing parameters was that it reduces the size of the number range from 0.05 to 0.3 for typical column sizes. This had numerical advantage in speed of calculation. The column shear strength $\left(V_{u}\right)$ is normalised by dividing by $B D \sqrt{ } f_{c k}$ to form the normalised shear strength $\left(K_{s}\right)$ represented by Eq. 10 . This normalisation has advantage because it provides a measure of the relative shear strength of the column, independent of column dimensions.

$$
K_{s}=\frac{V_{u}}{B D \sqrt{f_{c k}}}
$$

therefore

$$
V_{u}=K_{s} \sqrt{f_{c k}}(B / L)(D / L) L^{2}
$$

This can be represented as

$$
V_{u}=f_{2}\left[B / L, D / L, L, f_{c k}, K_{s}\right]
$$

Since the dynamic shear force $(V) \leq$ Shear capacity $\left(V_{u}\right)$

$$
f_{1}\left[W, B / L, D / L, L, I_{t} / I_{g}, f_{c k}, S D\right] \leq f_{2}\left[B / L, D / L, L, f_{c k}, K_{s}\right]
$$


To solve this equation $f_{1}$ and $f_{2}$ are plotted against stand-off distance, hence $W, B / L, D / L, L, I_{t}, f_{c k}$ and $K_{s}$ are constant and the intersection point (Fig. 1) can be obtained. The SSD is mathematically represented by equation (9) for clearing:

$$
S S D_{\text {shear }}=f\left[W, B / L, D / L, L, I_{t} / I_{g}, f_{c k}, K_{s}\right]
$$

and equation (10) for no clearing:

$$
S S D_{\text {shear }}=f\left[W, D / L, L, I_{t}, f_{c k}, K_{s}\right]
$$

From these equations it is clear that SSD as related to shear failure depends on charge weight, concrete strength, $B / L, D / L, L, I_{t}$ and $K_{s}$. Using the above method a database of SSD's for shear and flexure were generated using the following range of variables: charge weight $\{230,500,1000,1500$, $1800,4500 \mathrm{~kg}\}, f_{c k}$ ranging from 20 to $40 \mathrm{~N} / \mathrm{mm}^{2}$, B/L ranging from 0.05 to $0.3, \mathrm{D} / \mathrm{L}$ ranging from 0.05 to 0.3 , L ranging from 2.5 to $6 \mathrm{~m}$, normalised shear strength $\left(K_{s}\right)$ ranging from 0.1 to 0.8 and normalised flexural strength ranging from 0.1 to 0.8 . The concrete strengths are low, particularly for old structures in developed countries; however the 20 to $40 \mathrm{~N} / \mathrm{mm}^{2}$ range is more realistic for buildings in developing regions where concrete strengths are often lower. The parametric study provided an array of approximately 300,000 data points upon which a regression analysis was based. A series of the regression analysis functions were developed and used in a parametric study to explore the range of the safe scaled distance for columns adopted in practice. The functions (SSD equations) yield the maximum R-squared values of 0.996 and 0.994 to estimate the SSD of a column for clearing and no clearing respectively. A total of 396 columns were examined based on a combination of the following parameters: $B\{300,450,600 \mathrm{~mm}\}, D\{300,450,600 \mathrm{~mm}\}, L\{3,4,5,6 \mathrm{~m}\}$, diameter of main reinforcement $\{20,25,32 \mathrm{~mm}\}$, number of main rebars $\{4,8 \mathrm{~mm}\}, 2$ and 4 legged ties-with $12 \mathrm{~mm}$ rebars, spacing of ties $\{150,200,250 \mathrm{~mm}\}$ and axial compression of 10,20 and $30 \%$ of $A_{g} f_{c k}$. The shear and flexural strength of these columns was estimated using BS 8110 (BSI, 1997) without any material safety factors. 


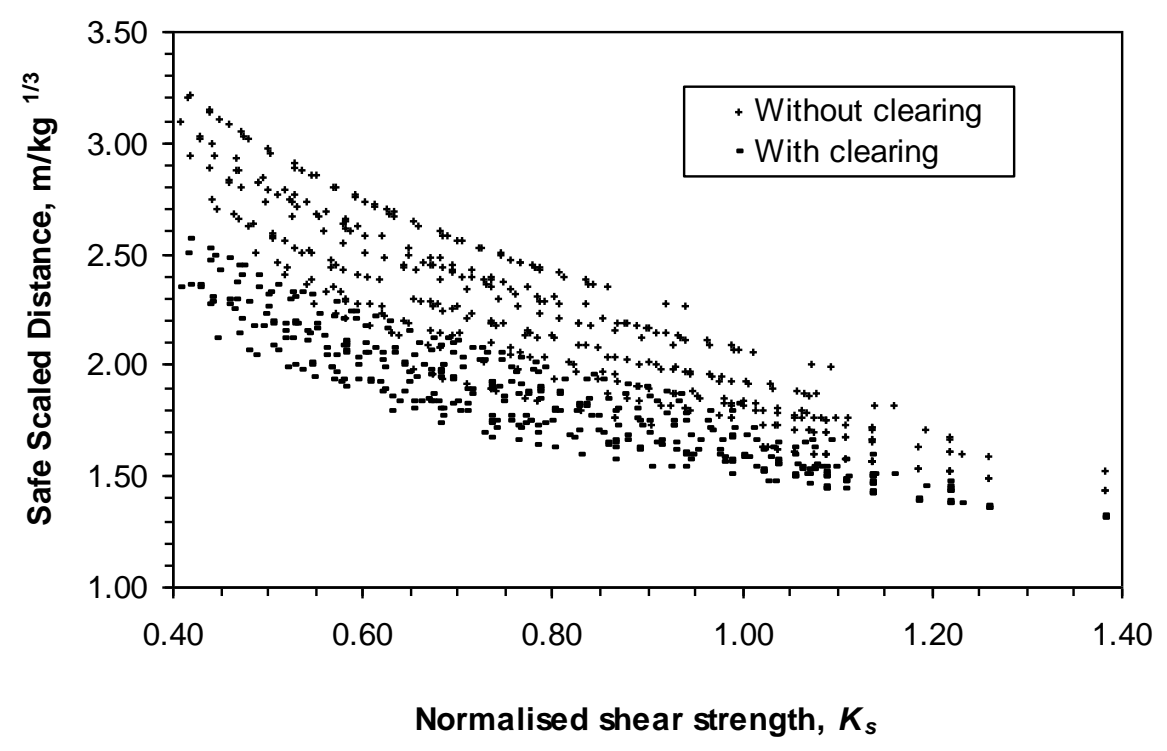

Fig. 5 Normalised shear strength vs. safe scaled distance

\section{Results from the parametric study}

Fig. 5 shows SSD plotted against the normalised shear strength of the 396 columns considered, each with and without clearing. An equivalent graph is available showing SSD versus the normalised flexural strength (Sakthivel, 2008) although since shear failure was found to be critical in all cases the flexural graph is not included. Shear failure tends to be critical for columns due to a number of factors which include: (a) columns tend to have low shear resistance, and (b) the higher modes of vibration contribute significantly to the dynamic shear force, whereas the higher modes of vibration do not contribute significantly to the dynamic bending moments.

The mean value of SSD determined from these data was $1.84 \mathrm{~m} / \mathrm{kg}^{1 / 3}$ with clearing and $2.20 \mathrm{~m} / \mathrm{kg}^{1 / 3}$ without clearing. It is interesting to compare these values with those from other sources. As discussed previously Christopherson (1945) concluded from his extensive investigations that the scaled distance of most interest to designers was within the limit of $1.98 \mathrm{~m} / \mathrm{kg}^{1 / 3}$. More recently, finite element modelling using LS-DYNA by Wu and Hao (2007) provided a critical SSD of $1.8 \mathrm{~m} / \mathrm{kg}^{1 / 3}$ where column axial forces are low and $1.18 \mathrm{~m} / \mathrm{kg}^{1 / 3}$ where column axial forces are high. The reason for the variation with axial compression is because compression enhances the shear strength of the column. This parametric study assumed axial compression was developed from a loading of $1.0 \mathrm{x}$ dead load $+1 / 3^{\text {rd }}$ of the imposed loading and this produced axial compression forces of the order of $10-25 \%$ of $A_{g} f_{c k}$. This corresponds to a low value of axial force from the Wu and Hao study; hence the scaled distance of $1.8 \mathrm{~m} / \mathrm{kg}^{1 / 3}$ is the most appropriate value for comparison purposes. Therefore the results of both Christopherson and $\mathrm{Wu}$ and Hao are close to those from the present investigation. The forensic analysis presented in this study indicated that the Murrah Building required a SSD of 
$1.95 \mathrm{~m} / \mathrm{kg}^{1 / 3}$, which again fits comfortably with $\mathrm{Wu}$ and Hao $\left(1.8 \mathrm{~m} / \mathrm{kg}^{1 / 3}\right)$ and Christopherson $\left(1.98 \mathrm{~m} / \mathrm{kg}^{1 / 3}\right)$ values. It is worth noting that blast loading can in certain circumstances create tensile loading in columns and effect would reduce the shear capacity of the columns considerably. Uplift effects from blast on conventional buildings are not understood in sufficient detail to allow them to be included in this study. They are however worthy of future study and they have the potential to reduce the safe scaled distance significantly.

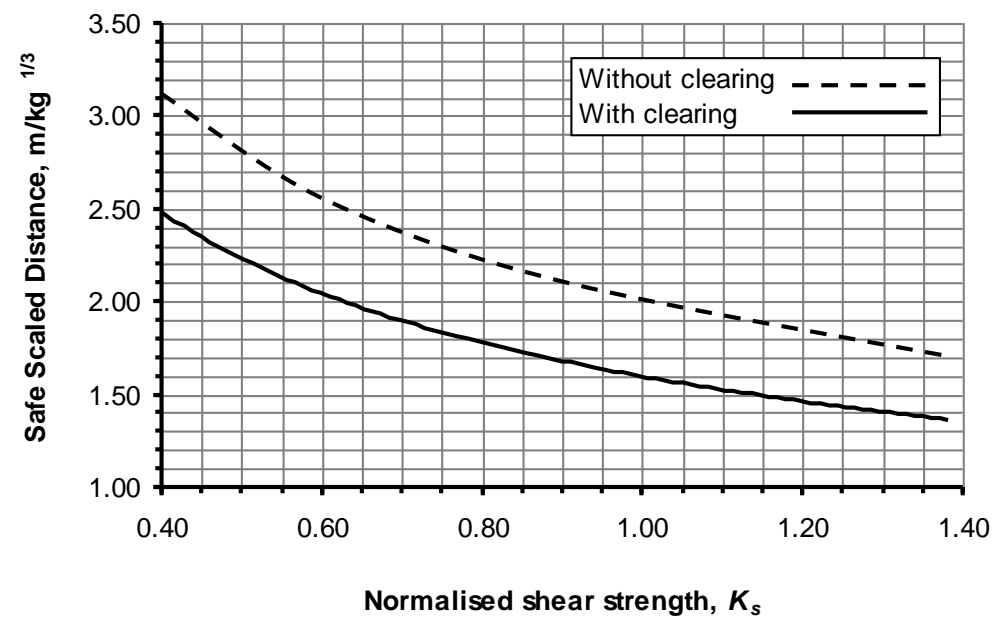

Fig. 6: Normalised shear strength vs. safe scaled distance design chart for r.c. columns

The US DoD (DoD, 2004) provide a SSD value of $4.46 \mathrm{~m} / \mathrm{kg}^{1 / 3}$ for unstrengthed framed structures. This appears to be conservative, at least in respect of the column failure criteria. However this value is designed to provide a basic level of protection from effects such as secondary fragmentation, which are not within the scope of this parametric study. In the congested urban environment achieving a SSD of $4.46 \mathrm{~m} / \mathrm{kg}^{1 / 3}$ can be problematic, in which case a basic level of protection against column failure is of interest. In this circumstance the SSD can be established approximately for a given column using the normalised shear strength vs. SSD design chart presented in Fig. 6. This shows the trend-lines obtained from the parametric values presented in Fig. 5. It should be noted that uplift can occur during blast loading and this will reduce the compression force in the columns. Therefore, the reduced shear strength due to the loss of compression may need to be included when calculating the normalised shear strength for use with this chart. It should also be noted that this chart contains no factors of safety.

\section{Conclusions}

The safe scaled distance within which r.c. columns can be expected to fail is of interest when developing security measures for buildings, since column failure is normally required before progressive collapse can be initiated. This paper develops an iterative method for establishing the critical distance within which r.c. columns can be expected to fail. This distance is presented in terms of scaled distance and this approach has the built in flexibility to account for variations in charge size. 
Using this method a series of functions were developed from which the safe scaled distance could be determined for a given charge size, column geometry and set of material properties. These functions were used to establish the safe scaled distances for a set of 396 columns, each with and without clearing of blast pressure. The results were used to develop a design chart for estimating the safe scaled distance for columns. This allows for a rapid estimation of the stand-off distance required to safeguard against column failure, inclusive of an allowance for the relative strength of the column. The results from the study have been found to be in good agreement with other studies, which included a World War II investigation into the performance of structures subjected to blast and a more recent LS-Dyna based study. The method was also shown to correctly predict the failure modes that occurred when the Murrah Building was subjected to blast loading.

\section{References}

Baker JF (1948) The design of framed buildings against high explosive bombs. The civil engineer in war. Vol. III: Properties of materials, structures, hydraulics, tunneling and surveying. Institution of Civil Engineers, London, 80-113.

Biggs M (1964) Introduction to Structural Dynamics. McGraw-Hill Inc., New York, USA.

BSI (1997) BS 8110-1. Structural use of concrete, Part 1: Code of Practise for design and construction. BSI London, UK

Brode HL (1955) Numerical solution of spherical blast waves. Journal of Applied Physics, No.6.

Byfield MP (2004) Design of steel framed buildings at risk from terrorist attack. The Structural Engineer, 82, (22), 31-38.

Byfield MP (2006) Behaviour and design of commercial multistory buildings subjected to blast. J. Perform. Constr. Fac., 204, 324-329.

Byfield MP and Paramasivam S (2011) The Murrah building collapse: a reassessment of the transfer girder. Journal of Performance of Constructed Facilities (doi:10.1061/(ASCE)CF.19435509.0000227)

Chopra AK (2001) Dynamics of Structures: Theory and Applications to Earthquake Engineering. Prentice Hall, NJ, USA.

Christopherson DG (1945) Structural Defense. London: Ministry of Home Security Research \& Experiments Department.

Corley WG et al (1998) The Oklahoma City bombing: Summary and recommendations for multihazard mitigation. J. Perf. Constr. Fac., 12(3), 100-112.

Cranz C (1926). Lehrbuch der Ballistik, Springer-Verlag, Berlin.

Henrych J (1979) The Dynamics of Explosion and Its Use. Elsevier Scientific Publishing Company, Amsterdam.

Hopkinson B (1915) British Ordnance Board Minutes, 13565. 
Kingery CN and Bulmash G (1984) Airblast parameters from TNT Spherical Air Blast and Hemispherical Surface Blast, Technical Report ARBRL-TR-02555. US Armament Research and Development Centre, Ballistic Research Laboratory, Aberdeen Proving Ground, MD.

Paramasivam S (2008) Protective Design against Disproportionate Collapse of RC and Steel Framed Structures. Thesis (PhD), Univ. of Southampton, Southampton, UK.

Smith P Byfield MP and Goode J (2010) Building robustness research during World War II. Journal of Performance of Constructed Facilities, Vol. 24, No. 6, December 1.

US DoD (2004) Ammunition and explosives safety standards. DoD 6055. 9-STD, Assistant Secretary of Defence, Washington, D.C.

U.S. DoD (2008) Structures to Resist the Effects of Accidental Explosions. UFC 3-340-02, Washington, D.C.

Wu C and Hao H (2007) Safe Scaled Distance for Masonry Infilled RC Frame Structures subjected to Airblast Loads. J. Perf. Constr. Fac., ASCE, 21(6), 422-431. 